\title{
Ammonia Diffusion through Nalophan Double Bags: Effect of Concentration Gradient Reduction
}

\author{
Selena Sironi, Lidia Eusebio, Laura Capelli, Emanuela Boiardi, and Renato Del Rosso \\ Department of Chemistry, Materials and Chemical Engineering “Giulio Natta”, Politecnico di Milano, 20133 Milan, Italy \\ Correspondence should be addressed to Selena Sironi; selena.sironi@polimi.it
}

Received 14 July 2014; Revised 3 October 2014; Accepted 4 November 2014; Published 24 November 2014

Academic Editor: Ki-Hyun Kim

Copyright (C) 2014 Selena Sironi et al. This is an open access article distributed under the Creative Commons Attribution License, which permits unrestricted use, distribution, and reproduction in any medium, provided the original work is properly cited.

\begin{abstract}
The ammonia loss through Nalophan bags has been studied. The losses observed for storage conditions and times as allowed by the reference standard for dynamic olfactometry (EN 13725:2003) indicate that odour concentration values due to the presence of small molecules may be significantly underestimated if samples are not analysed immediately after sampling. A diffusion model was used in order to study diffusion through the bag. The study discusses the effect of concentration gradient $(\Delta C)$ across the polymeric membrane of the analyte. The $\Delta C$ was controlled by using a setup bag called "double bags." Experimental data show a reduction of ammonia percentage losses due to the effect of the external multibarrier. The expedient of the double bag loaded with the same gas mixture allows a reduced diffusion of ammonia into the inner bag. Comparing the inner bag losses with those of the single bag stored in the same conditions $(T, P, u)$ and with equal geometrical characteristics $(S / V, z)$, it was observed that the inner bag of the double bag displays a $16 \%$ loss while the single bag displays a $37 \%$ loss. Acting on the $\Delta C$ it is possible to achieve a gross reduction of $57 \%$ in the ammonia leakage due to diffusion.
\end{abstract}

\section{Introduction}

The development of both industrial and agricultural areas, coupled with the increase of population density, has brought about in some regions the forced coexistence between production sites and residential areas. One of the outcomes of this fact is the increased attention on air quality, involving detailed monitoring of ambient air in the area. Specifically, the focus is on the olfactory nuisance, which considered as a consequence of the chemical plants operation urged the scientific community and the lawmakers to consider odour as an air pollutant. In fact it has been found that the olfactory nuisance, besides being annoying for the population, may be the direct cause of several pathologies such as nausea, headache, migraine, and psychological discomfort for the citizens living in the surroundings of an industrial or agricultural productive site.

Due to the necessity of preserving an acceptable air quality level, especially in residential areas close to industrial plants, that are odour-emitting sources, a scientific methodology was devised in order to reliably quantify odour, the so-called dynamic olfactometry [1]. Thus the European
Community stepped in producing a regulation concerning this new science, the norm EN13925 [2].

With olfactometric analysis it is possible to quantify odour concentration in air samples coming from the sites of interest by means of a panel of people chosen in accordance with the norm EN1375 [2]. Due to the complications entailed with on-site olfactometric analyses, samples are usually collected at the source and then stored in a suitable container until they are analysed in a dedicated laboratory $[1,3-6]$.

As for the recovery and conservation of the odorous compounds the standard prescribes to use bags with specific characteristics in order to avoid as much as possible contamination of sample, deterioration, and osmotic diffusion out of the bags [7].

The sample bags must meet the quality requirements of EN 13725, in order to preserve the odour sample for (at least) 30 hours.

The European Standard on dynamic olfactometry (EN13925) [2] states the general requirements relevant to the materials used for the realization of sampling equipment. According to the European Standard, the materials used 
for storing compounds for olfactometric analyses shall be odourless; furthermore, they shall be selected so to minimize the physicochemical interactions between sample components and bag materials, also the materials ought to have minimal permeability in order to reduce sample losses caused by diffusion, and last but not least the bag should have a smooth internal surface.

The materials allowed for the manufacturing of sample containers (bags), as listed in Section 6.3.1 of the actual standard, are tetrafluoroethylene hexafluoropropylene copolymer (FEP), polyvinylfuoride (PVF, Tedlar), and polyethyleneterephthalate (PET, Nalophan).

According to the European Standard these materials should be tested for suitability, by verifying whether or not they can store a mixture of odourants with minimal variations in odour and composition for times of storage of 30 hours, which is the maximum storage time allowed by the European Standard.

Lately a lot of researches have been done on these "allowed bag materials" prescribed by the norm [8-22] in order to evaluate their performances. Results highlighted a nonnegligible diffusion across the bag wall with respect to certain substances, particularly for small or water-soluble molecules such as ammonia $\left(\mathrm{NH}_{3}\right)$ and hydrogen sulphide $\left(\mathrm{H}_{2} \mathrm{~S}\right)[7,10,11,14,23,24]$.

For these reasons, the new German guideline for odour sampling (VDI 3880) limits sample storage to $6 \mathrm{~h}$ only, as also discussed by Laor et al. [25, 26].

Apart from polymeric films like Tedlar, Nalophan, and Teflon, many studies $[5,8-10,14,17,18,21,22]$ focused on researching both new materials and new superficial treatments to apply to the films, already contemplated in the norm EN13725, in order to obtain a suitable product for sampling and storage of odorous gaseous mixtures, usually made of volatile organic compounds (VOC), capable of meeting the strict requirements imposed by the European regulation.

Kim et al. [5, 8] have performed an assessment of polycoupled films polyester-aluminium (PEA) performances. Comparing the results obtained with PEA and those obtained with Tedlar, it was highlighted that the first one assures higher recovery as far as nonaromatic compounds are concerned [8]. Other researchers have studied the behaviour of polymeric films such as PET, both with a plasma [8] superficial treatment $[21,22]$ and with a poly-coupling with different materials (e.g., FlexFoil (PET-NY-AL-CPE) [9, 10, 14, 18]). Anyway, to this day a material has not yet been found suitable for effectively storing for 30 hours a gaseous mixture of VOCs like those that can be encountered in many different problematic industrial areas such as landfills and dumps, foundries, intensive rearing sites, biomass anaerobic digestion plants, and refineries. The diffusion of a gaseous mixture through polymeric films is driven by a large number of different factors; here the most significant ones are reported as an example:

(i) the characteristics of the polymeric film constituting the storage bag, both geometrical and physicochemical, such as the wall thickness, the crystallinity grade of the polymer, and the orientation of the polymeric structure [7, 27-29];

(ii) the bag's surface to filling volume ratio (Fick's law) [24];

(iii) the conditions at which the sample is stored (temperature and humidity) and the concentration gradient across the membrane, that is, the film (Permeability law, Fick's law) [23].

The aim of the present work is to investigate a new possible bag design in order to minimize the diffusion of small watersoluble molecules through Nalophan films. The original idea is a new structure bag design called "double bag" that is particular sampling bag made of two concentric films barrier filled with the same gaseous mixture. For this purpose, even high concentration of ammonia does not play a fundamental role in the total odour measured, and the behaviour of a small molecule with a structure similar to the water as ammonia is considered. The final goal is, starting from the analysis of Fick's law, to mitigate diffusive phenomena trying to reduce as much as possible the difference in concentration $(\Delta C)$ across the polymeric membrane of the analyte.

\section{Materials and Methods}

2.1. Materials. The Nalophan polymer used to realize the bags employed for the experimental tests consists of a one-layer foil of polyterephthalic ester copolymer with $20 \mu \mathrm{m}$ thickness supplied by Tilmmanns S.p.A (Milan, Italy).

A single bag was obtained starting from a tubular film with a diameter of $22.5 \mathrm{~cm}$, which was then cut in different lengths. One end was equipped with a clamp closure while the other end was provided with a Teflon inlet tube for sample collection (Figure 1(a)).

The double bags were obtained starting from two different tubular films cut in different lengths. The inner bag was obtained from a tubular film with a diameter of $22.5 \mathrm{~cm}$, while the outer one was obtained from a tubular film with a diameter of $31 \mathrm{~cm}$.

The double bag is a two-concentric-bags design composed (Figure 1(b)) of an inner bag with a capacity of $6000 \mathrm{~cm}^{3}$ and surface equal to $2580 \mathrm{~cm}^{2}$ and an outer bag with a capacity of $12000 \mathrm{~cm}^{3}$ and surface equal to $5208 \mathrm{~cm}^{2}$. The different volumes are meant to create an interspace between the two bags. The double bag was realized following this procedure,

(i) One end of the inner bag was equipped with a clamp closure while the other end was provided with a Teflon inlet tube for sample collection.

(ii) The outer bag was clamped on the Teflon inlet tube of the inner bag and on the other side was provided with a Teflon inlet tube for sample collection.

The $\mathrm{NH}_{3}$ decay over time was evaluated using a gas chromatography (GC) technique for the quantification of $\mathrm{NH}_{3}$ concentration inside the bag. The ammonia concentration was measured using a HP Agilent 6890 gas chromatograph equipped with an Agilent HP-5MS fused silica capillary 


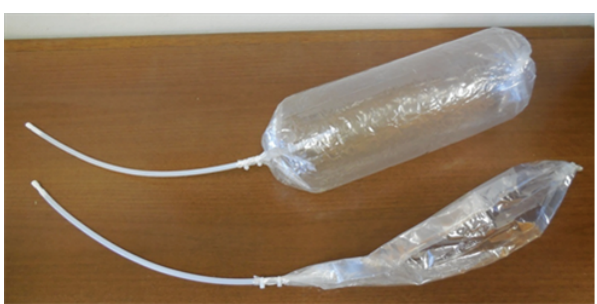

(a)

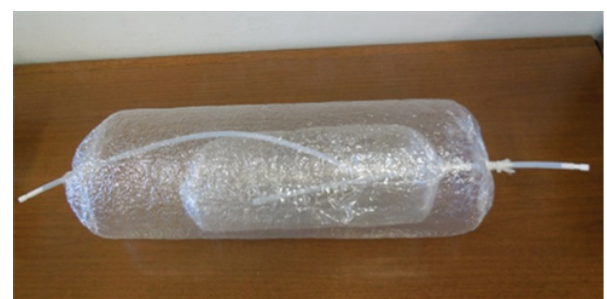

(b)

FIgURE 1: Nalophan bags: (a) single bag and (b) double bags.

column (CP 7591-PoraPlot Amines, length $25 \mathrm{~m}$, internal diameter $0.32 \mathrm{~mm}$, and film thickness $10 \mu \mathrm{m}$ ). The oven temperature follows a three-step program: $100^{\circ} \mathrm{C}$ for 12 minutes, from $100^{\circ} \mathrm{C}$ to $200^{\circ} \mathrm{C}$ with a rate of $8^{\circ} \mathrm{C} / \mathrm{min}$, and $200^{\circ} \mathrm{C}$ for 5 minutes. The carrier gas was helium with a constant flow of $3 \mathrm{~mL} / \mathrm{min}$ (a pressure of $1.21 \mathrm{~atm}$ and a mean velocity of $53 \mathrm{~cm} / \mathrm{s}$ ). The gaseous mixture inside the bags was analysed with the GC, equipped with a TCD detector, at specific time intervals, in order to evaluate the variations of $\mathrm{NH}_{3}$ concentration ( $\mathrm{ppm}$ ) over time.

A calibration curve was traced to correlate the area of the GC peak with the $\mathrm{NH}_{3}$ concentration (ppm). Instrument calibration was performed analysing different standard concentrations of $\mathrm{NH}_{3}$ in air ranging from 10,000 to $60,000 \mathrm{ppm}$. Standards were obtained starting from different liquid mixtures of $\mathrm{NH}_{3}$ in water and analysing the headspace obtained in a fixed volume of air where the liquid was fluxed and then stored at a controlled temperature. The liquid phases were prepared at room temperature $\left(20^{\circ} \mathrm{C}\right)$ mixing from $4 \mathrm{~mL}$ to $11 \mathrm{~mL}$ of a liquid solution of $\mathrm{NH}_{3}$ at a concentration of $30 \% \mathrm{w} / \mathrm{w}$ and $50 \mathrm{~mL}$ of distilled water according to Field and Combs [30].

All the tested samples were realized by filling the Nalophan bags with a gaseous mixture of ammonia in wetair, with an ammonia concentration of about $55,000 \mathrm{ppm}_{\mathrm{V}}$ and a relative humidity of $60 \%$, which will be defined as the "test mixture." The high concentrations were chosen to stress ammonia diffusion phenomena through the film. The test mixture was prepared using the headspace technique. The liquid phase was prepared at room temperature $\left(20^{\circ} \mathrm{C}\right)$ mixing $10.5 \mathrm{~mL}$ of a liquid solution of $\mathrm{NH}_{3}$ at a concentration of $30 \% \mathrm{w} / \mathrm{w}$ and $50 \mathrm{~mL}$ of distilled water.

During storage time, physical parameters like temperature and relative humidity were kept under control using a climatic chamber (Chamber GHUMY by Fratelli Galli, Milano, Italy).

2.2. Methods. All tests were performed measuring the $\mathrm{NH}_{3}$ concentration at different times after sample preparation. More specifically, $\mathrm{NH}_{3}$ was analysed, every hour, from 0 to $26 \mathrm{~h}$. Each measurement involved the withdrawal of $300 \mu \mathrm{L}$ of the test mixture by means of a syringe and the injection of the taking in the GC.

The diffusion of ammonia was evaluated through Nalophan bags having, respectively, (i) a capacity of about $6000 \mathrm{~cm}^{3}$ and a surface equal to $2580 \mathrm{~cm}^{2}$ for the single bag,

(ii) a capacity of about $6000 \mathrm{~cm}^{3}$ and a surface equal to $2580 \mathrm{~cm}^{2}$ for the inner bag,

(iii) a capacity of about $12000 \mathrm{~cm}^{3}$ and a surface equal to $5208 \mathrm{~cm}^{2}$ for the outer bag.

All the bags were filled with $6000 \mathrm{~cm}^{3}$ of the above defined test mixture and then stored at a constant temperature of $23^{\circ} \mathrm{C}$ and an external relative humidity of $60 \%$. The external relative humidity was set equal to the internal relative humidity in order to avoid water diffusion during storage and its potential influence on ammonia diffusion.

\section{Calculations}

The diffusion phenomena through a polymeric film are described by Fick's law. According to this theory, the specific molar flow is defined as

$$
j=-D \frac{\partial C}{\partial x}
$$

where

(i) $j$ is the specific molar flux $\left(\mathrm{mol} / \mathrm{m}^{2} / \mathrm{s}\right)$,

(ii) $D$ is the diffusion coefficient (molecular diffusivity) of the compound through the film $\left(\mathrm{m}^{2} / \mathrm{s}\right)$,

(iii) $C$ is the concentration of the diffusing compound $\left(\mathrm{mol} / \mathrm{m}^{3}\right)$,

(iv) $\partial x$ is the differential thickness of the film.

The film thickness can be therefore expressed as

$$
\int_{0}^{z} d x=z
$$

where $z$ is the film thickness (m).

In the expression above (1), only the main direction is considered, moving from the gradient to the single derivative of $C$.

Referring to Figure 2, which schematizes the diffusion phenomenon through a multilayer thin film which constitutes the sampling bag, we can define the following: 


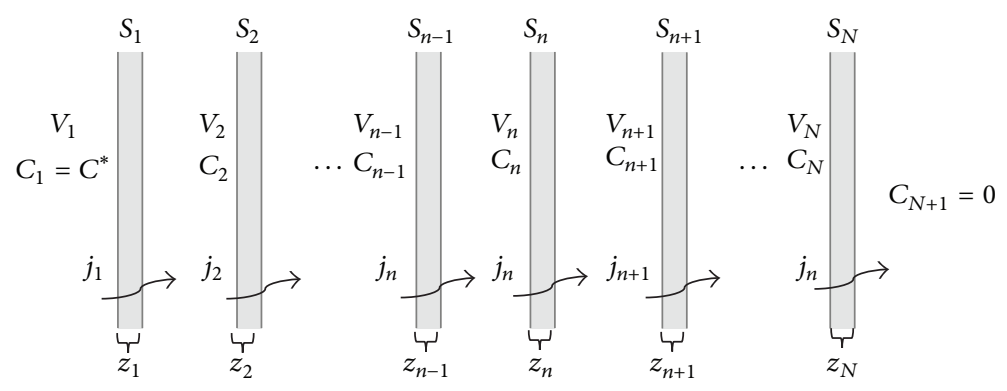

FIgURE 2: Schematization of diffusion through the multilayer thin film of the bag.

(i) $S_{n}$ is the surface of the $n$-polymeric film $\left(\mathrm{m}^{2}\right)$;

(ii) $z_{n}$ is the thickness of the $n$-film (m);

(iii) $C_{n}$ is the concentration inside the $n$-volume $\left(\mathrm{mol} / \mathrm{m}^{3}\right)$

(iv) $C_{N+1}$ is the concentration outside the film $\left(\mathrm{mol} / \mathrm{m}^{3}\right)$; for a single bag it is generally considered negligible $\left(C_{N+1}=0\right)$;

(v) $j_{n}$ is the specific molar flow through the $n$-film $\left(\mathrm{mol} / \mathrm{m}^{2} / \mathrm{s}\right)$.

If the film thickness can be considered negligible, then the accumulation term inside the material is negligible as well.

With this assumption, a generic $j_{n}$ turns out to be constant across the film ( $x$ for $0<x<z)$.

By integrating (1) in $d x$ between 0 and $z_{n}$, the specific molar flow $j_{n}$ can be expressed as

$$
j_{n}=-D \frac{C_{n+1}-C_{n}}{z_{n}} .
$$

Note that $j_{n}$ is relevant to an infinitesimal portion of the exchange surface $d S$.

Assuming that the internal molar concentration of the $n$-bag, $C_{n}$, is constant inside the whole internal volume $V_{n}$ and also the external concentration $C_{n+1}$ is constant inside the external volume $V_{n+1}$, then the global flow $J$ through the exchange surface $S_{n}$ can be calculated by integrating as follows:

$$
\begin{gathered}
J=\int_{0}^{S_{n}} j_{n} d S \\
J=S_{n} j_{n} .
\end{gathered}
$$

In order to obtain a general equation describing the diffusion trough the multilayer barrier system, a molar mass balance was written on the $n$-volume:

$$
\frac{\partial M_{n}}{\partial t}=J_{n-1}-J_{n}
$$

Combining (5) with (6), the evolution of molar content in the volume $V_{n}$ may be calculated from the molar flow through the $n$ surface and $n-1$ surface:

$$
\begin{aligned}
\frac{\partial M_{n}}{\partial t} & =\frac{\partial C_{n} V_{n}}{\partial t}=j_{n-1} S_{n-1}-j_{n} S_{n} \\
& =\left(-D S_{n-1} \frac{C_{n}-C_{n-1}}{z}+D S_{n} \frac{C_{n+1}-C_{n}}{z}\right) \\
\frac{\partial M_{n}}{\partial t}=- & \frac{D}{z}\left(\left(S_{n-1}+S_{n}\right) C_{n}-S_{n-1} C_{n-1}-S_{n} C_{n+1}\right) .
\end{aligned}
$$

The general conditions applying both to the multilayer system and to the specific case, linking the two situations, are as follows:

(i) when $n \leq 1$, it is considered that the concentration of the multilayer inner bag is equal to $C^{*}$,

(ii) when $1<n<N$, it is considered that the concentration of the concentric bag containing the inner one is equal to $C_{n}$,

(iii) when $n>N$, it is considered that the concentration outside the outer bag of the multilayer system is negligible $\left(C_{n}=0\right)$,

where $N$ is the number of the concentric bags.

The multilayer film model could represent the double bag considering a multilayer system with $N$ equal to $2(N=2)$.

In the case considered of the double bag, the outer surface $\left(S_{n}\right)$ is twice the inner surface:

$$
S_{n}=2 S_{n-1}
$$

Combining (8) and (9), considering the general conditions reported above, the molar flow through the inner bag $(n=1)$ can be expressed as

$$
\begin{aligned}
\frac{\partial M_{n}}{\partial t} & =\frac{\partial C_{n} V_{n}}{\partial t} \\
& =-\frac{S_{n-1} D}{z}\left(3 C_{1}-C_{1}-2 C_{2}\right)=-\frac{S_{n-1} D}{z}\left(2 C_{1}-2 C_{2}\right)
\end{aligned}
$$


while the flow through the outer bag $(n=2)$ can be expressed as

$$
\begin{aligned}
\frac{\partial M_{n}}{\partial t} & =\frac{\partial C_{n} V_{n}}{\partial t} \\
& =-\frac{S_{n-1} D}{z}\left(3 C_{2}-C_{1}-0\right)=-\frac{S_{n-1} D}{z}\left(3 C_{2}-C_{1}\right) .
\end{aligned}
$$

Considering the same filling volume for the inner and the outer bags, the concentration trends over time will be described by the following expressions:

$$
\begin{gathered}
\text { Inner Bag: } \frac{\partial C_{N-1}}{\partial t}=-\frac{S_{n-1} D}{z V_{N}}\left(2 C_{N-1}-2 C_{N}\right) \\
\text { Outer Bag: } \frac{\partial C_{N}}{\partial t}=-\frac{S_{n-1} D}{z V_{N}}\left(3 C_{N}-C_{N-1}\right)
\end{gathered}
$$

Equations (12a) and (12b) constitute a system of differential homogeneous equations of the first order (ODE) that could be rewritten as

$$
\begin{aligned}
& \text { Inner Bag : } y_{1}^{\prime}=2 k y_{1}-2 k y_{2}, \\
& \text { Outer Bag : } y_{2}^{\prime}=-k y_{1}+3 k y_{2},
\end{aligned}
$$

where

$$
y_{i}^{\prime}=\frac{\partial C_{i}}{\partial t} \quad k=-\frac{S_{n-1} D}{z V_{N}} \quad y_{i}=C_{i} .
$$

The solution of the system of differential homogeneous equation of the first order is an exponential function such as

$$
\vec{y}=\sum_{i=1}^{n} C_{i} e^{\lambda_{i} t} \overrightarrow{u_{k}}
$$

The matrix's eigenvalues $\left(\lambda_{i}\right)$ are

$$
\lambda_{1}=4 k \quad \lambda_{2}=k
$$

and the eigenvectors $\left(\overrightarrow{u_{k}}\right)$ are

$$
\vec{u}_{1}=\left(\begin{array}{c}
-1 \\
1
\end{array}\right) \quad \vec{u}_{2}=\left(\begin{array}{l}
2 \\
1
\end{array}\right) .
$$

The boundary conditions required for solving the equations system (13) can be set as

$$
\begin{array}{ll}
y_{1}(t)=C_{0} & \text { per } t=0 . \\
y_{2}(t)=C_{0} & \text { per } t=0 .
\end{array}
$$

Using $\lambda_{i}, \overrightarrow{u_{k}}$ and the boundary conditions, substituting in (15), the concentration trends over time for the double bag follow these expressions:

$$
\begin{aligned}
& C_{1}(t)=-\frac{1}{3} C_{0} e^{\lambda_{1} t}+\frac{4}{3} C_{0} e^{\lambda_{2} t}, \\
& C_{2}(t)=\frac{1}{3} C_{0} e^{\lambda_{1} t}+\frac{2}{3} C_{0} e^{\lambda_{2} t}
\end{aligned}
$$

where

(i) $C_{1}(t)$ is the concentration trend for the inner bag,

(ii) $C_{2}(t)$ is the concentration trend for the outer bag.

Moreover, for the double and single bag comparison purpose the multilayer film model could represent the single bag considering a multilayer system with $N$ set equal to one $(N=1)$. In the case of a single bag, the surface $S_{n}$ is equal to the surface $S_{n-1}$. Combining (8) with the general condition reported above, the molar flow through the single bag $(n=1)$ can be expressed as

$$
\frac{\partial M_{n}}{\partial t}=-\frac{D S_{n}}{z} C_{1} .
$$

The concentration trends over time can be then expressed as

$$
\frac{\partial C_{1}}{\partial t}=-\frac{D S_{n}}{V_{n} z} C_{1} .
$$

The theoretical dissertation concerning the single bag is here simply reported, since it has been discussed in detail in a previous work [24].

The concentration trend over time for the single bag is

$$
\frac{C}{C_{0}}=e^{-\left(S_{n} D / V_{n} z_{n}\right) t} .
$$

\section{Results and Discussion}

Table 1 shows ammonia concentration values measured in terms of ppms, at different instants in the time domain and ammonia loss in terms of percentage points for two different setups: a double bag (DB) and a single bag (SB).

Columns one and two in Table 1 contain the concentrations and the percentage losses of ammonia over time, respectively, for the inner bag $\left(\mathrm{DB}_{\text {in }} 6000-2580\right)$ with a $V_{n}$ equal to $6000 \mathrm{~cm}^{3}$ and a $S_{n-1}$ equal to $2580 \mathrm{~cm}^{2}$. Columns three and four show the concentrations and the percentage losses of ammonia over time, respectively, for the outer bag $\left(\mathrm{DB}_{\text {out }} 6000-5280\right)$ filled with a $V_{n}$ equal to $6000 \mathrm{~cm}^{3}$ and a $S_{n}$ equal to $5280 \mathrm{~cm}^{2}$. Columns five and six provide the concentrations and the percentage losses of ammonia over time, respectively, for the single bag (SB 6000-2580) with a $V_{n}$ equal to $6000 \mathrm{~cm}^{3}$ and a $S_{n}$ equal to $2580 \mathrm{~cm}^{2}$ just like the inner one for the double bag case.

Exploiting the system of (19), the percentage ammonia loss over time for the inner bag $\left(\mathrm{NH}_{3 \text { loss\% inner }}\right)$ and for the outer one $\left(\mathrm{NH}_{3 \text { loss\%_outer }}\right)$ can be estimated being equal to, respectively,

$$
\begin{aligned}
\mathrm{NH}_{\text {3loss\%_inner }} & =\left(1-\frac{C_{1}}{C_{0}}\right) * 100 \\
& =\left(1+\frac{1}{3} e^{\lambda_{1} t}-\frac{4}{3} e^{\lambda_{2} t}\right) * 100, \\
\mathrm{NH}_{\text {3loss\%_outer }} & =\left(1-\frac{C_{2}}{C_{0}}\right) * 100 \\
& =\left(1-\frac{1}{3} e^{\lambda_{1} t}+\frac{2}{3} e^{\lambda_{2} t}\right) * 100
\end{aligned}
$$


TABLE 1: Experimental data relevant to $\mathrm{NH}_{3}$ diffusion over time in Nalophan bags: the inner double bags $\left(\mathrm{DB}_{\text {in }} 6000-2580\right)$ have $V_{n}=$ $6000 \mathrm{~cm}^{3}$ and $S_{n-1}=2580 \mathrm{~cm}^{2}$, the outer double bags $\left(\mathrm{DB}_{\text {out }} 6000-5280\right)$ have $V_{n}=6000 \mathrm{~cm}^{3}$ and $S_{n}=5280 \mathrm{~cm}^{2}$, and the single bag is with $V_{n}=6000 \mathrm{~cm}^{3}$ and $S_{n}=2580 \mathrm{~cm}^{2}$.

\begin{tabular}{|c|c|c|c|c|c|c|}
\hline \multirow{2}{*}{ Time $[\mathrm{h}]$} & \multicolumn{2}{|c|}{$\mathrm{DB}_{\text {in }} 6000-2580$} & \multicolumn{2}{|c|}{$\mathrm{DB}_{\text {out }} 6000-5280$} & \multicolumn{2}{|c|}{ SB 6000-5280 } \\
\hline & ppm & $\mathrm{NH}_{3 \text { loss } \% \text { inner }}$ & ppm & $\mathrm{NH}_{3 \text { loss} \% \text { outer }}$ & ppm & $\mathrm{NH}_{3 \text { loss } \%}$ \\
\hline 0 & 55000 & 0,00 & 55000 & 0,00 & 54714 & 0,00 \\
\hline 1 & 54973 & 0,05 & 49283 & 10,39 & 54698 & 0,03 \\
\hline 2 & 54075 & 1,68 & 52952 & 3,72 & 54652 & 0,11 \\
\hline 3 & 53176 & 3,32 & 47120 & 14,33 & 51625 & 5,65 \\
\hline 4 & 54217 & 1,42 & 53264 & 3,16 & 50334 & 8,00 \\
\hline 5 & 52569 & 4,42 & 48394 & 12,01 & 48393 & 11,55 \\
\hline 6 & 54971 & 0,05 & 43929 & 20,13 & 45778 & 16,33 \\
\hline 7 & 51775 & 5,86 & 42715 & 22,34 & 49613 & 9,32 \\
\hline$\vdots$ & $\vdots$ & $\vdots$ & $\vdots$ & $\vdots$ & $\vdots$ & $\vdots$ \\
\hline 20 & 51286 & 6,75 & 35201 & 36,00 & $\vdots$ & $\vdots$ \\
\hline$\vdots$ & $\vdots$ & $\vdots$ & $\vdots$ & $\vdots$ & $\vdots$ & $\vdots$ \\
\hline 23 & 48553 & 11,72 & 30089 & 45,29 & 36034 & 34,14 \\
\hline 24 & 48180 & 12,40 & 30233 & 45,03 & 34878 & 36,25 \\
\hline 25 & 46453 & 15,54 & 31007 & 43,62 & 36033 & 34,14 \\
\hline 26 & 46137 & 16,11 & 26136 & 52,48 & 34248 & 37,41 \\
\hline
\end{tabular}

while from (22) it is possible to compute the percentage loss of ammonia over time for the single bag:

$$
\mathrm{NH}_{3 \mathrm{loss} \%}=1-\frac{C}{C_{0}}=1-e^{-\left(S_{n} D / V_{n} z_{n}\right) t}
$$

The analyses of these data provide some useful insights. The single bag scenario shows a loss of ammonia after 26 hours equal to the $37 \%$ of the initial amount. The percentage ammonia loss after 26 hours with respect to the inner bag is $16 \%$. Since the inner bag is identical in size and filling to the single bag, the ratios $(S / V)$ in the two cases will be also identical and equal to $0.43 \mathrm{~cm}^{-1}$. A comparison of the ammonia losses over time in the two situations highlights a significant difference: the ammonia loss is much smaller for the inner bag (16\%) with respect to the one observed for the single bag (37\%). Thus it is possible to say that reducing the transmembrane concentration difference $(\Delta C)$, across the polymeric film, achieved by making use of the double bag, the ammonia leakage can be effectively reduced, after 26 hours, by $57 \%$.

Finally, the ammonia loss of the outer bag is $52 \%$. Differences in ammonia loss for single bag (37\%) and outer bag $(52 \%)$ are due to the difference in $S / V$ as observed by Sironi et al. [24].

As shown in Figure 3, the concentration trend expressed as $C / C_{0}$ can be plotted against time for the double bag case. Experimental data show a good agreement with the expected trend in accordance with the system of (19). In order to compute the trend described in theory by the model's equations (19), the specific diffusivity parameter of $\mathrm{NH}_{3}$ was employed through Nalophan $\left(D_{\mathrm{NH}_{3}}^{\mathrm{Nalo}}\right)$ as evaluated by Sironi et al. that is equal to $2.38 * 10^{-8} \mathrm{~cm}^{2} / \mathrm{s}$ [24].

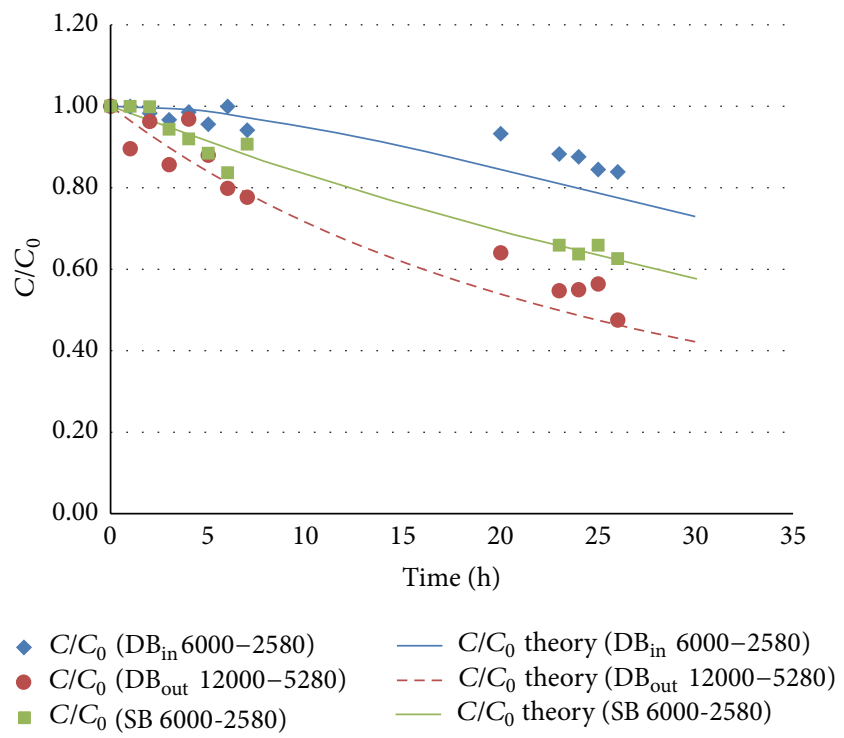

FIgURE 3: Concentration profile of $\mathrm{NH}_{3}$ over time for double bag: experimental data (dots) versus theoretical trend (continuous line). The inner Nalophan bags $\left(\mathrm{DB}_{\text {in }} 6000-2580\right)$ have $V_{n}=6000 \mathrm{~cm}^{3}$ and $S_{n-1}=2580 \mathrm{~cm}^{2}$, while the outer $\left(\mathrm{DB}_{\text {out }} 6000-5280\right)$ have $V_{n}=$ $6000 \mathrm{~cm}^{3}$ and $S_{n}=5280 \mathrm{~cm}^{2}$.

\section{Conclusions}

In the present work diffusive phenomena were investigated for a new sampling bag configuration that is the so-called double bag, capable of reducing the trans polymeric membrane concentration difference $(\Delta C)$ of the analyte. In the mathematical formulation of Fick's law, the $(\Delta C)$ is a parameter critical to the estimation of the diffusive material flux 
$(j)$. It is possible to modify this $(\Delta C)$ utilizing two concentric sampling bags, both filled with the same gaseous mixture so to realize a cavity between the storage inner bag $\left(\mathrm{DB}_{\text {in }} 6000-\right.$ $2580)$ and the external environment capable of reducing the $(\Delta C)$.

The examination of the results highlights that this new configuration for the storage device is effective for the reduction of ammonia losses from the bag. Comparing the inner bag losses with those of the single bag, since the two are commensurate in terms of both tests conditions ( $T, P$, $u$ ) and geometrical characteristics of the bag $(S / V, z)$, it was observed that the inner bag of the double bag displays a $16 \%$ loss while the single bag a $37 \%$ loss. Thus, it can be concluded that acting on the $(\Delta C)$ it is possible to achieve a gross reduction of $57 \%$ in the ammonia leakage due to diffusion.

As a final remark, it is important to highlight once more that the structure of the double bag has with no doubts several advantages with respect to the common single bags as far as gaseous odorous mixtures storage is concerned. The double bag configuration is expected to reduce losses observed for other VOCs using the same equation, the same bags configuration, and specific diffusion coefficient.

\section{Conflict of Interests}

The authors declare that there is no conflict of interests regarding the publication of this paper.

\section{References}

[1] L. Capelli, S. Sironi, R. Del Rosso, P. Céntola, and S. Bonati, "Improvement of olfactometric measurement accuracy and repeatability by optimization of panel selection procedures," Water Science and Technology, vol. 61, no. 5, pp. 1267-1278, 2010.

[2] Comitee for European Normalization, "Air quality-determination of odour concentration by dynamic olfactometry," European Standard EN 13725:2003 (E), ICS 13.040.99, Comitee for European Normalization, Brussels, Belgium, 2003.

[3] A. H. Bokowa, "The effect of sampling on the measured odour concentration," Chemical Engineering Transactions, vol. 23, pp. 43-48, 2008.

[4] W. Bourgeois, A. C. Romain, J. Nicolas, and R. M. Stuetz, "The use of sensor arrays for environmental monitoring: interests and limitations," Journal of Environmental Monitoring, vol. 5, no. 6, pp. 852-860, 2003.

[5] Y.-H. Kim and K.-H. Kim, "Experimental approach to assess sorptive loss properties of volatile organic compounds in the sampling bag system," Journal of Separation Science, vol. 35, no. 21, pp. 2914-2921, 2012.

[6] Y. Laor, Y. Ozer, U. Ravid, A. Hanan, and P. Orenstein, "Methodological aspects of sample collection for dynamic olfactometry," Chemical Engineering Transactions, vol. 23, pp. 55-60, 2010.

[7] L. Capelli, S. Sironi, and R. del Rosso, “Odor sampling: techniques and strategies for the estimation of odor emission rates from different source types," Sensors (Switzerland), vol. 13, no. 1, pp. 938-955, 2013.

[8] Y.-H. Kim, K.-H. Kim, S.-H. Jo, E.-C. Jeon, J. R. Sohn, and D. B. Parker, "Comparison of storage stability of odorous VOCs in polyester aluminum and polyvinyl fluoride Tedlar bags," Analytica Chimica Acta, vol. 712, pp. 162-167, 2012.
[9] N. Akdeniz, K. A. Janni, L. D. Jacobson, and B. P. Hetchler, "Comparison of gas sampling bags to temporarily store hydrogen sulfide, ammonia, and greenhouse gases," Transactions of the ASABE, vol. 54, pp. 653-661, 2011.

[10] S. Beghi and J.-M. Guillot, "Sample water removal method in volatile organic compound analysis based on diffusion through poly(vinyl fluoride) film," Journal of Chromatography A, vol. 1127, no. 1-2, pp. 1-5, 2006.

[11] S. Beghi and J.-M. Guillot, "Use of poly(ethylene terephtalate) film bag to sample and remove humidity from atmosphere containing volatile organic compounds," Journal of Chromatography $A$, vol. 1183, no. 1-2, pp. 1-5, 2008.

[12] S. Cariou and J.-M. Guillot, "Double-layer Tedlar bags: a means to limit humidity evolution of air samples and to dry humid air samples," Analytical and Bioanalytical Chemistry, vol. 384, no. 2, pp. 468-474, 2006.

[13] S. Ghosh, K.-H. Kim, and J. R. Sohn, "Some insights into analytical bias involved in the application of grab sampling for volatile organic compounds: a case study against used tedlar bags," The Scientific World Journal, vol. 11, pp. 2160-2177, 2011.

[14] J.-M. Guillot and S. Beghi, "Permeability to water vapour and hydrogen sulphide of some sampling bags recommended by EN 13725," Chemical Engineering Transactions, vol. 15, pp. 79-86, 2008.

[15] M. J. Hansen, A. P. S. Adamsen, A. Feilberg, and K. E. N. Jonassen, "Stability of odorants from pig production in sampling bags for olfactometry," Journal of Environmental Quality, vol. 40, no. 4, pp. 1096-1102, 2011.

[16] K.-H. Kim, "A study of sorptive loss patterns for reduced sulfur compounds in the use of the bag sampling method," Environmental Monitoring and Assessment, vol. 123, no. 1-3, pp. 259-269, 2006.

[17] J. A. Koziel, J. P. Spinhirne, J. D. Lloyd, D. B. Parker, D. W. Wright, and F. W. Kuhrt, "Evaluation of sample recovery of malodorous livestock gases from air sampling bags, solid-phase microextraction fibers, Tenax TA sorbent tubes, and sampling canisters," Journal of the Air \& Waste Management Association, vol. 55, no. 8, pp. 1147-1157, 2005.

[18] P. Mochalski, B. Wzorek, I. Śliwka, and A. Amann, "Suitability of different polymer bags for storage of volatile sulphur compounds relevant to breath analysis," Journal of Chromatography B: Analytical Technologies in the Biomedical and Life Sciences, vol. 877, no. 3, pp. 189-196, 2009.

[19] D. B. Parker, Z. L. Perschbacher-Buser, N. A. Cole, and J. A. Koziel, "Recovery of agricultural odors and odorous compounds from polyvinyl fluoride film bags," Sensors, vol. 10, no. 9, pp. 8536-8552, 2010.

[20] S. L. Trabue, J. C. Anhalt, and J. A. Zahn, "Bias of tedlar bags in the measurement of agricultural odorants," Journal of Environmental Quality, vol. 35, no. 5, pp. 1668-1677, 2006.

[21] A. P. Van Harreveld, "Odor concentration decay and stability in gas sampling bags," Journal of the Air and Waste Management Association, vol. 53, no. 1, pp. 51-60, 2003.

[22] C. Wang, P.-C. Lai, S. H. Syu, and J. Leu, "Effects of CF4 plasma treatment on the moisture uptake, diffusion, and WVTR of poly(ethylene terephthalate) flexible films," Surface and Coatings Technology, vol. 206, no. 2-3, pp. 318-324, 2011.

[23] S. Sironi, L. Eusebio, L. Dentoni, L. Capelli, and R. D. Rosso, "Ammonia diffusion through Nalophan bags," Water Science and Technology, vol. 69, no. 3, pp. 486-494, 2014.

[24] S. Sironi, L. Eusebio, L. Capelli, E. Boiardi, R. Del Rosso, and J. M. Guillot, "Ammonia diffusion phenomena through Nalophan 
bags used for olfactometric analyses," Journal of Environmental Protection, vol. 5, pp. 949-961, 2014.

[25] VDI, Olfactometry_Static Sampling_VDI 3880, Verein Deutscher Ingenieure, Düsseldorf, Germany, 2011.

[26] Y. Laor, D. Parker, and T. Pagé, "Measurement, prediction, and monitoring of odors in the environment: a critical review," Reviews in Chemical Engineering, vol. 30, pp. 139-166, 2014.

[27] I. O. Igwe, C. M. Ewulonu, and I. Igboanugo, "Studies on the diffusion characteristics of some aromatic solvents into polypropylene film," Journal of Applied Polymer Science, vol. 102, no. 2, pp. 1985-1989, 2006.

[28] I. Mallia, Sviluppo di una Nuova Metodologia per la Misura della Permeabilità di Film Plastici ad uso Alimentare, Dipartimento di Ingegneria Agraria-Sezione Meccanica, Università Degli Studi di Catania, Catania, Italy, 2010.

[29] L. Piergiovanni and S. Limbo, "Proprietà chimiche dei materiali di packaging," in Food packaging, pp. 11-20, Springer, Milan, Italy, 2010.

[30] P. E. Field and R. J. Combs, “Aqueous ammonia vapor-liquid equilibria-entropy and temperature dependence of Wilson coefficients," Journal of Solution Chemistry, vol. 31, no. 9, pp. 719-742, 2002. 

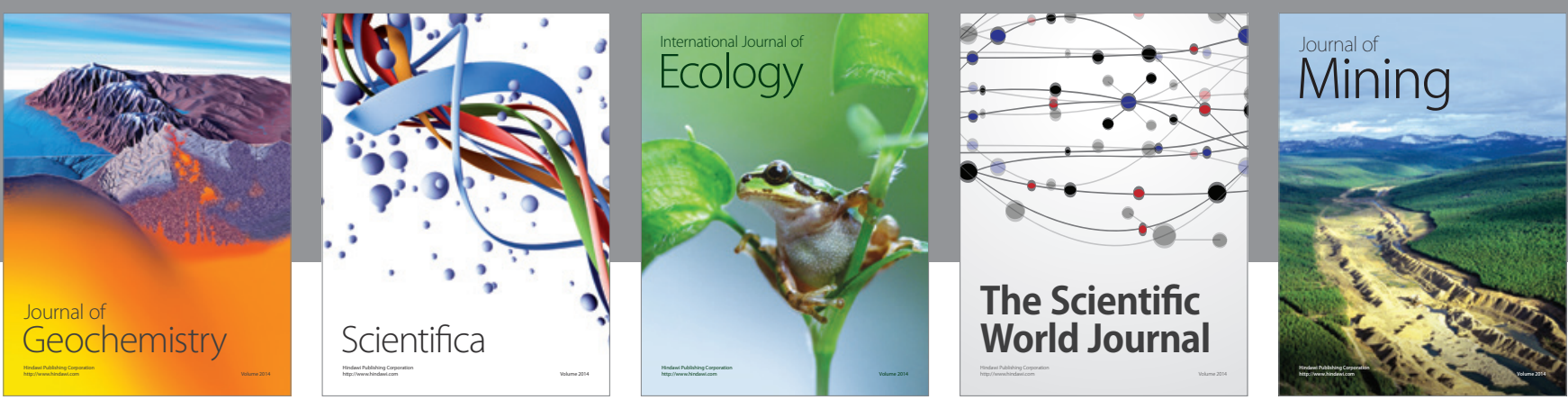

The Scientific World Journal
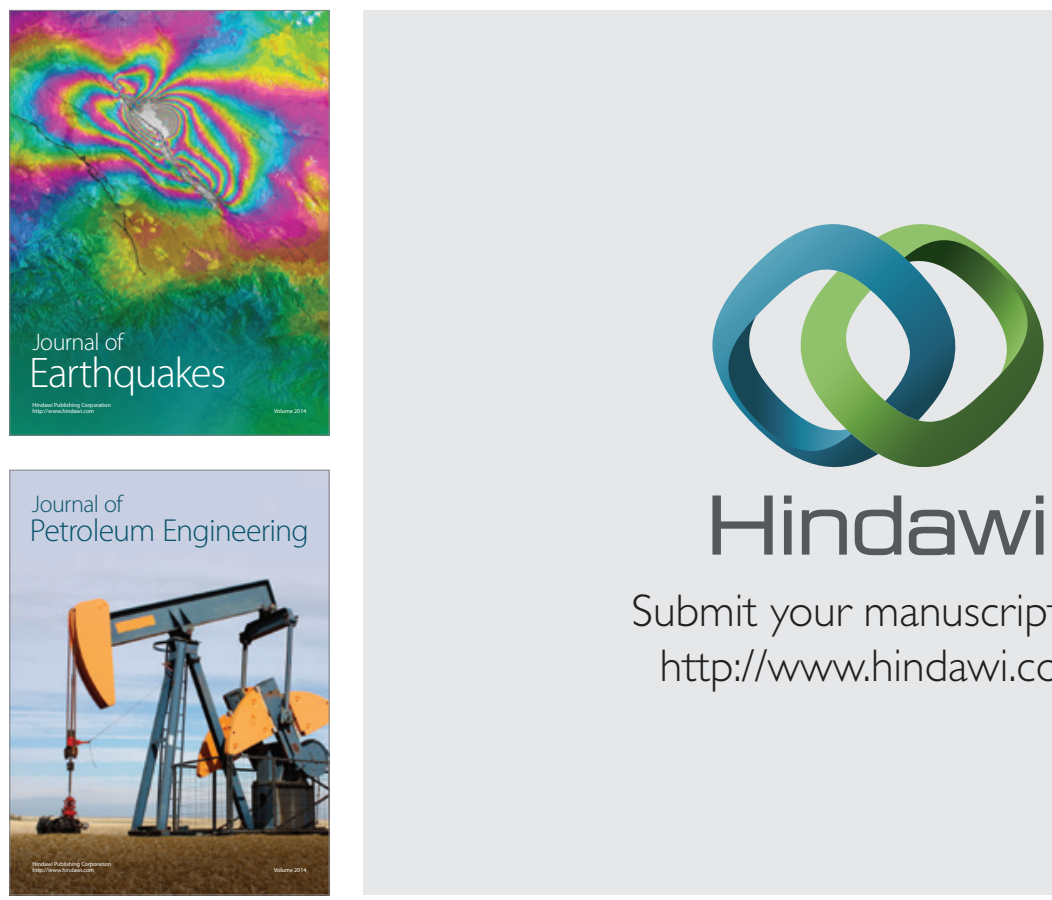

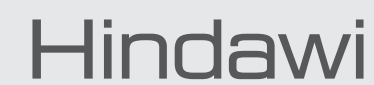

Submit your manuscripts at

http://www.hindawi.com
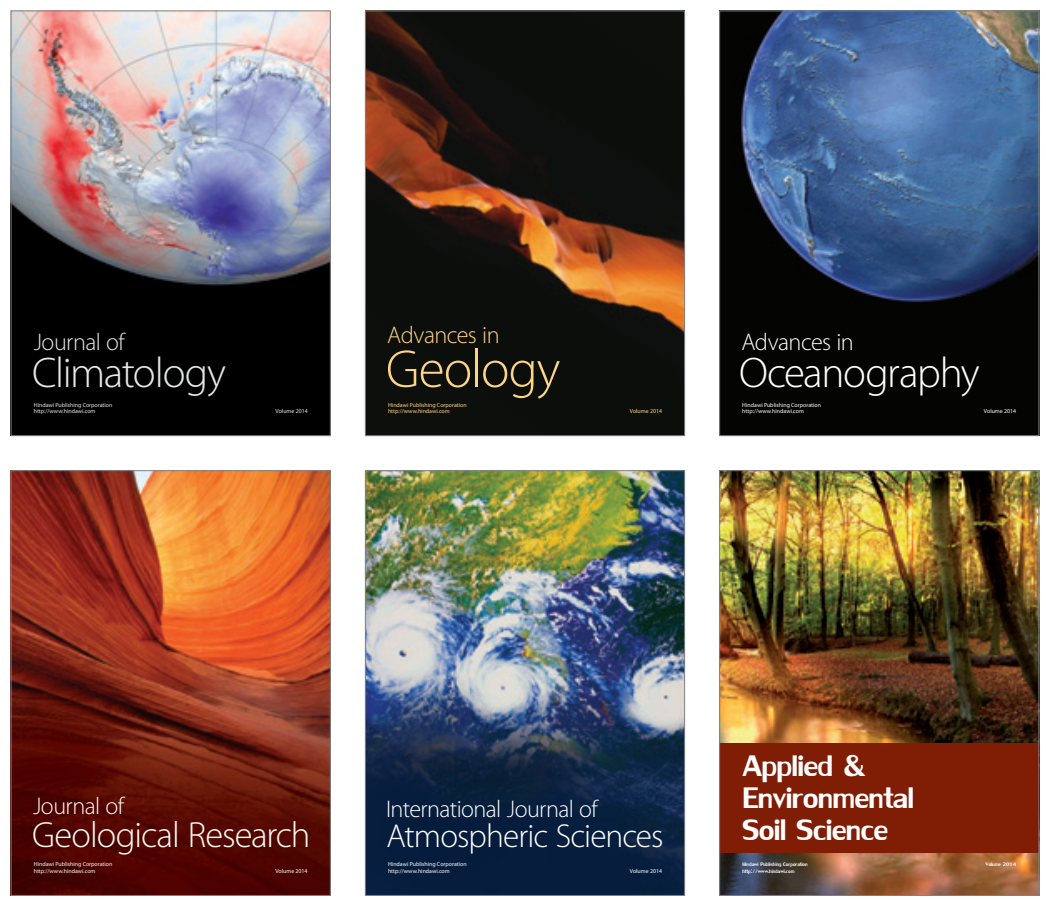
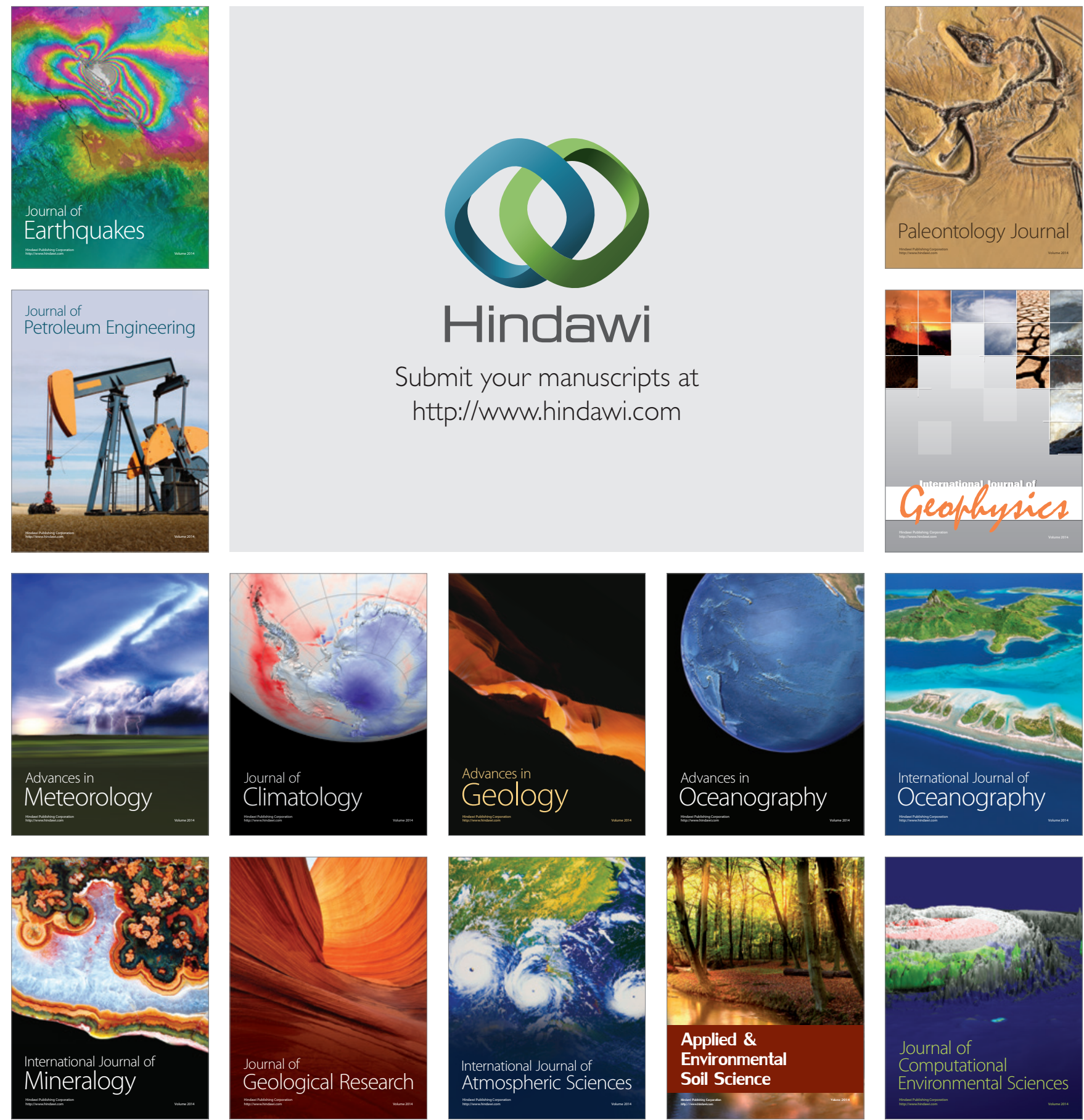